\title{
The Relationship between Emotional Intelligence (EQ) and Adversity Quotient (AQ)
}

\author{
Shrutika Verma ${ }^{1}$, Ankita Aggarwal ${ }^{2}$, Harshita Bansal ${ }^{3}$ \\ ${ }^{1,2,3}$ Amity Business School
}

\begin{abstract}
The purpose of this research is to determine a relationship between Emotional Quotient (EQ) and Adversity Quotient $(A Q)$. This research is qualitative in nature and based on the previous studies done on emotional intelligence $(E Q)$ and adversity quotient $(A Q)$. Adversity quotient is the ability of a person to manage high stress levels and ability to work efficiently in the adversity. Emotional intelligence can be defined as the ability of the person to understand their own and other people's emotions and feelings. After conducting the review, a brainstorming session was done to conclude a critical review.
\end{abstract}

Keywords: emotional quotient; adversity quotient

\section{Introduction}

Adversity Quotient is a term coined by Dr. Paul Stoltz and is defined as "the capacity of the person to deal with the adversities of his life. As such, it is the science of human resilience." It tells us how well one withstands adversity and his ability to triumph over it. Recent researches have shown that AQ is better in assessing success than IQ. The concept of AQ helps us in understanding how people react to challenges and different adversities in all the aspects of life. AQ basically comes from three different scientific fields namely: psychoneuroimmunology (mind- body relationship), neurophysiology (study of brain), and cognitive psychology (relationship between thoughts and feelings). These three are the building blocks for the adversity quotient. Psychoneuroimmunology deals with the feelings and emotions. Neurophysiology deals with how the brain learns and functions. Cognitive Psychology deals with the thoughts and feelings.

Emotional intelligence (EI) or emotional quotient (EQ) is the capability of individuals to recognize emotions of the people, to discriminate between different feelings of their own and other people and label them appropriately and adjust emotions to adapt environments or achieve one's goal. Michael Beldoch first coined the term in 1964 but it only became popular in a book in 1995 written by Daniel Goleman. Daniel Goleman is very popular and highly criticized in the scientific community. There are three main models of EI:

- Ability model

- Mixed model

- Trait model

Some of these measures and constructs, when considering all these models, may overlap and different people agree with different constructs. For example, emotions may interact with thinking and allow people to be better decision makers. A person who is more responsive emotionally to crucial issues will attend to the more crucial aspects of his or her life. Aspects of emotional facilitation factor is to also know how to include or exclude emotions from thought depending on context and situation.

\section{Literature Review}

Brutu et.al (2002) studied the degree of satisfaction of the employees in agricultural organization. The findings were there were a positive relationship between collaboration with top management and feedback from superiors. high compensation implies the high level of job satisfaction.

Brown (2004) studied the emotional intelligence on workplace. The findings IQ can help you to be successful to the extent of 20 percent only in life. The rest of 80 percent success depends on your EQ. With high level of emotional intelligence managers are able to identify talents among employees.

Parvathy (2005) studied the relationship between adversity quotient and academic problems among student's teachers. The finding was Adversity quotient can also help us to assess the Academic problems of students as students face a lot of challenges in their life and AQ helps to overcome these challenging situations.

Aydin (2009) studied the employee satisfaction in respect of spiritual leadership and organizational culture through emotional intelligence. The finding was employee satisfaction have a positive correlation between organizational culture and spiritual leadership.

Zahid (2000) studied the relationship between organizational emotional intelligence and their quality of service. The findings were there was clear implication for both employees and organization. There was low level of employee satisfaction. 
Chaudhary et.al (2010) studied the objective of this study was to identify the correlation between factors of HRD climate and employee engagement. Through this research, it was found that the general climate dimension of HRD climate was the most important forecaster of employee engagement irrespective of HRD mechanism dimension.

Khosravi et.al (2011) studied the objective of this study was to identify the relationship between manager's emotional intelligence level and effective delegation in industry. Through this research, it is found that with high emotional intelligence manager are able to identify the talent among employees more efficiently and are able to delegate the task according to their area of interest.

Kabir (2011) studied the job satisfaction of employees in different pharmaceutical companies. The finding was overall job satisfaction of the employees in pharmaceutical sector is at a positive level.

Aziri (2011) studied the impact of high level of emotional intelligence. The findings were managers with high EI level are able to identify talents among employees, decentralize the management process, then delegate tasks to staff, so the employees themselves will find this great opportunity to exploit and discover their talents.

Najafi et.al (2012) studied the impact of high emotional intelligence on solving problems and on technical experience. the findings higher level of emotional intelligence has high self-confidence, high concentration, are more successful in their job, more effective in their leadership style, and they are able to motivate their staff.

Jain et.al (2013) studied the objective of this study was to recognize the factors which influence the job satisfaction of employee and also find the factor which can improve the satisfaction of employees. The findings were employees were not satisfied with their organization and it gave the negative impact on the organization. Training, regular feedback, fair compensation, career development, safe working condition etc. can improve the satisfaction of employees.

Zhang et.al (2013) studied the relationship between organizational culture and employee satisfaction for Chinese family firm. Results are not ready yet to be generalized.

Sinha (2013) studied the satisfaction level of employees with special reference to KRIBHCO, Surat. The findings were welfare measures, role clarity, freedom of decision making and recognition at work are not the important factor that normally contribute to the employee satisfaction.

Gayathri et.al (2013) studied the different concepts of emotions and cognition and how it come in theory of emotional intelligence. The finding was to improve lifestyle of individual emotional intelligence is required and so as it also required that individual have control on their emotions and cognition.

Jain et.al (2014) studied the objective of this study was to understand the working condition of the employees the findings were employees of Dominos were satisfied with working environment, recreation activity but they were not satisfied by workload and overtime and attitude of their boss.

Gazzola (2014) studied the implementation of CSR program and impact on employees. The finding was CSR trigger attitude and behavior at workplace which affect organizational performance.

Mwangi et.al (2014) studied whether emotional intelligence influence to employee engagement in public university or not. The finding was emotional intelligence influences employee engagement.

Dhankar (2015) studied the acquiring methods and unique quotient of the subject with the help of Dermatoglyphic Multiple Intelligence Test. The finding was revealed the unique quotient of the subject and the best suitable acquisition method for the subject.

Young Woo et.al (2015) studied the relationship between emotional intelligence and the adversity quotient of nurses and office workers. The finding was, there were statistically significant differences in the adversity quotient and emotional intelligence between nurses and office workers. Along with nurses had a lower adversity quotient than office workers.

Quang et.al (2015) studied the application of leaders through emotional intelligence. The finding was emotional intelligence has a great influence to retain the leadership and also to develop the workforce engagement.

Gupta (2015) studied the adversity quotient of the students who are going to enter in higher education. The findings adversity quotient was not influenced by gender or steam, it only influenced with the type of school.

Koražija et.al (2015) studied the relationship between spiritual intelligence and work satisfaction among employees and employers. the findings were there were no significant relationship between spiritual intelligence and work satisfaction for employers whereas there was a positive relationship they were found in aspect of employees.

Aggarwal et.al (2015) studied the relationship between spirituality, emotional intelligence and employee engagement. The findings were there were no significant relationship between spiritual intelligence and work satisfaction for employers whereas there was a positive relationship they were found in aspect of employees.

Islam (2016) studied the employee empowerment on employee satisfaction and quality of services. The finding was there was clear implication for both employees and organization. There was low level of employee satisfaction.

Choudhary (2016) studied the strategies for strengthen the organizational culture. The finding was there was a difficulty in the common workplace which was faced by employees on regular basis. 


\section{Critical Review}

Adversity Quotient is considered to be the determinant of superior performance and success. Adversity Response Profile (ARP) is the assessment instrument designed by Stoltz and it is a valid predictor of one's success, stress-threshold, performance, risk taking, capacity for change, productivity, perseverance, improvement, energy, and health. The responses comprise of four CORE dimensions where " $\mathrm{C}$ " stands for Control, "O" stands for Ownership, "R" stands for Reach and "E" stands for Endurance and the average ARP score is 147.5. Based on the responses the people falls under the category of either Pessimists or Optimists. The people who have low score can also improve their AQ using LEAD (listen, Explore, Analyze and Do something) formulated also formulated by Dr. Stoltz. Listen: It is how a person responds to adversity. Explore: Know the root cause of the problem and take responsibility. Analyze: Intelligently think of the situation and Do Something: Work out a plan of action and evaluate the result.

Good AQ of a person indicates that the person can fight against all the odds and achieve success. AQ helps us to understand many other factors like self-esteem, motivation, fighting spirit, creativity, sincerity, positive attitude, optimism, emotional stability. Adversity quotient can also help us to assess the Academic problems of students as students face a lot of challenges in their life and AQ helps to overcome these challenging situations. A student who is able to live through these difficult times will ultimately be able to achieve his/her goals. AQ can be improved of the person has empathy, sympathy and if the person is able to understand other's emotions.

Adversity quotient also helps to determine social skills of the students. It is observed that if the AQ increases then Social skills also increases and vice versa. All the students generally have an average level of social skills (in terms of Emotional Expressivity (EE) \{encoding nonverbal messages\}, Emotional Sensitivity (ES) \{decoding nonverbal messages\}, Emotional Control (EC) \{control and regulate nonverbal displays\}, Social Expressivity (SE) \{verbal expression\}, Social Sensitivity (SS) \{interpret others' verbal communications\} and Social Control (SC) \{social role playing\}). There may be instances in student's life which are uncontrollable, meaningless, unworthy and painful, but it is unto them whether to take it negatively or positively. AQ does not depend on age, gender or course of student. Students who want to improve their AQ score can follow LEAD formula for better results. The ability of an individual student to adapt to social interactions helps an individual to overcome different challenges in life.

Adversity Quotient and achievement motivation also has a relationship. However, not all the dimensions of adversity quotient were found to influence the achievement motivation. Achievement motivation is attaining success and achieving all aspirations in life. Achievement goals can affect the way a person performs a task and represent a desire to show competence. Age, gender does not affect the achievement motivation. There is a significant relationship between control, ownership and motivation for achievement. It is found that people with high level of control and ownership have high level of motivation for achievement. It is also found that people who have high level of AQ have high level of achievement motivation. It is also found that people who have high level of reach and endurance have high level of inner resource. People with high level of AQ have high level of interpersonal strengths as well. People with low level of AQ have low level of work habits.

One discovery indicated that average educational leaders had significantly lower adversity quotients. It is important to note that adversity quotient is not situational or likely to be changed over the course of one's life without proper awareness and training to strengthen one's CORE and response ability. Adversity quotient can fundamentally influence one's career choice, regardless of industry, passion for one's work, the difficulty one is willing to take on, and one's patience with inertia Adversity Quotient and Income: AQ is a predictor of wealth. Many studies have revealed a strong relationship between the AQ and incomes of entrepreneurial investors. Higher AQ people appear to earn more. Adversity Quotient and Hiring: The high-AQ employees tended to outperform the low-AQ employees. Now many industries are moving toward measuring the AQ of every applicant. There are many ways to improve the AQ radar:

- AQ on television: As you watch a television drama or sitcom, listen to what the characters say when faced with adversity or even a minor challenge.

- AQ on radio: As you listen to talk shows and the news, pay close attention to what people say in describing or responding to disasters, setbacks, or crises.

- AQ in conversation: Turn on your AQ radar during meetings, phone calls, and casual conversations. Pay attention to how people describe the challenges of their days, as well as what they think, say, and do about difficulties of all sizes.

- Reading for AQ: As you read newspapers, magazines, and books, look for specific quotations indicating what different people say when faced with adversity.

- AQ in art: As you watch dance, examine paintings, scrutinize sculptures, and view Performances, look for any indications of what is being communicated 
- AQ on the net: As you surf the Internet, explore advertisements and analyze the language people use to explain their business and themselves. Pay attention to how certain Web sites grant you control and ownership, and how some provide ways to deal with any adversities that may arise.

The ARP tool can be used by sectors to check their employees Adversity Quotient Level and if AQ Profiling is used in the Recruitment and Selection Process one can identify the level of AQ the candidates possess at the Initial stage itself and can have a choice to select or reject a candidate, hence leading to the right fit of the candidate to the right place. It also helps the candidates to improve their resilience by checking their AQ levels thereby reduce talent leakage in the system. AQ helps to develop potential performance leaders for growth of the organization by having the attrition rate controlled as Human Resources is a definite key to success to compete in today's cut throat competitive market.

Adversity quotient also helps to predict the job performance when it is compared with the wellestablished Big five model (Extraversion, Conscientiousness, Emotional Stability, Agreeableness, and Openness to Experience). All the dimensions of the Big five model related to specific aspects of human behavior which are independent of each other. This could be done by using the ARP. The ARP might not be able to predict job performance but in theoretical aspect, a pattern can be seen which leads to the formation of AQ and ARP measure will be required to measure the applicability in work related situations. But further research is required in this area.

\section{Conclusions}

Adversity quotient plays a major role when deciding whether a person would be able to manage and work effectively under stress and adverse conditions or not. While emotional intelligence plays a major role when identifying the emotions and helps people to understand the emotions effectively. Both of them are important aspects to be dealt with when considering top level managers as they need to effectively understand and recognize the emotions of their employees and as they will have adverse conditions each and every day in their work and personal life and will need to focus each and every day. Many studies have concluded a positive relationship and high correlation between adversity quotient and emotional intelligence. But previous literature is not enough and further research needs to be done when considering adversity quotient.

\section{References}

[1]. Aydin, B. (2009). A Research Analysis on Employee Satisfaction in terms of Organizational Culture and Spiritual Leadership, 159168.

[2]. Branch, M. (2011). The Relationship between Emotional Intelligence and Effective Delegation, 2(19), $223-236$.

[3]. Chaudhary, R. (n.d.). Relation between human resource development climate and employee engagement: Results from India, 7(4), 664-685.

[4]. Chaudhry, A. A., \& Usman, A. (2011). An investigation of the relationship between employees' emotional intelligence and performance, 5(May), 3556-3562. https://doi.org/10.5897/AJBM10.1430

[5]. Conte, J. M. (2005). A review and critique of emotional intelligence measures. Journal of Organizational Behavior, 26(4), 433440. https://doi.org/10.1002/job.319

[6]. Crawford, L. E. D., \& Chua Tee Teo. (2000). Promoting adversity quotient among Singaporean school children. React, 2000(1), $10-14$.

[7]. Dr Usha Parvathy, Praseeda M., IOSR Journal of Humanities and Social Science (IOSR-JHSS) Volume 19, Issue 11, Ver. VII (Nov. 2014), PP 23-26 e-ISSN: 2279-0837, p-ISSN: 2279-0845. www.iosrjournals.org

[8]. Dr Usha Parvathy1. (2014). Relationship between Adversity Quotient and Academic Problems among Student Teachers $\backslash n$. IOSR Journal of Humanities and Social Science (IOSR-JHSS), 19(11), 23-26. Retrieved from http://www.iosrjournals.org/iosrjhss/papers/Vol19-issue11/Version-7/D0191172326.pdf

[9]. Elizabeth Le Thi, may 2007 master thesis, psykologiske institute university of Oslo

[10]. Gayathri, N., \& Meenakshi, K. (2013). A Literature Review of Emotional Intelligence. International Journal of Humanities and Social Science Invention, 2(3), 42-51. https://doi.org/10.13189/ujm.2015.030401

[11]. Hema, G., \& Gupta, S. M. (n.d.). Adversity Quotient for Prospective Higher Education.

[12]. Jarman, K. (2008). Relationship of Emotional Intelligence of Healthcare Leaders and Measures of Employee Satisfaction and Turnover.

[13]. Jorfi, H., Fauzy, H., Yaccob, B., \& Shah, I. (2011). Human Resource Management - Emotional Intelligence: Communication Effectiveness mediates the Relationship between Stress Management and Job Satisfaction, 3(4), 1-7.

[14]. Kanagalakshmi, L., \& Aggarwal, V. (2015). Influence of Spirituality and Emotional Intelligence on Employee Engagement. Indian Journal of Applied Research, 5(9), 41-43.

[15]. Kaur, S. (2014). IMPACT OF WORK ENVIRONMENT ON JOB, 4(1), 1-8.

[16]. Lazovic, S., \& Studies, B. (2012). the Role and Importance of Emotional Intelligence in 2 . Emotional Intelligence and Leadership. Management, Knowledge and Learning, 797-805.

[17]. McDonald, C., \& McDonald, C. (2015). The Relationship between Senior Healthcare Executives' Emotional Intelligence and Employee Satisfaction This is to certify that the doctoral dissertation by.

[18]. Mousavi, S. H., Yarmohammadi, S., Nosrat, A. B., \& Tarasi, Z. (2012). The relationship between emotional intelligence and job satisfaction of physical education teachers, 3(2), 780-788.

[19]. Mwangi, C. I. (2014). Emotional Intelligence Influence on Employee Engagement Sustainability in Kenyan Public Universities, 1(1), 75-92. https://doi.org/10.6007/IJARPPG/v1-i1/920

[20]. Nowack, K., \& Ph, D. (2003). Leadership, Emotional Intelligence and Employee Engagement: Creating a Psychologically Healthy Workplace, 1-13. 
[21]. Quang, H. N., Khuong, M. N., \& Le, N. H. (2015). The Effects of Leaders' Emotional Intelligence on Employee Engagement in Vietnamese Construction Companies - A Case of Hoa Binh Corporation, 3(8). https://doi.org/10.7763/JOEBM.2015.V3.279

[22]. Sciences, E., \& Sciences, E. (2012). Studying the Effect of Emotional Quotient on Employee' s Job Satisfaction (The Case of Isfahan University of Medical Sciences), 343-355.

[23]. Shivaranjini. (2014). Adversity Quotient: One stop solution to combat attrition rate of women in Indian IT sector. International Journal of Business and Administration Research Review, 1(5), 181-189.

[24]. Sidhu, H. K. (2012). AN EXAMINATION OF RELATIONSHIP BETWEEN EMOTIONAL INTELLIGENCE, EMPLOYEE ENGAGEMENT, ETHICAL IDEOLOGY AND JOB PERFORMANCE.

[25]. Singh, J. K. (2013). A STUDY OF EMPLOYEES' JOB SATISFACTION AND ITS, 1(4), 105-111.

[26]. T, P. R. N., \& Narashiman, K. (n.d.). Emotional Intelligence and Work Performance: A Conceptual Study, $62-68$.

[27]. Well-being, D. O. F. (2012). ISSN: 2249-0558 DETERMINANT OF WELL-BEING AND EMPLOYEE ISSN: 2249-0558, 2(8), 322-339.

[28]. Woo, H. Y., \& Song, J. H. (2015). The Factors Affecting the Adversity Quotient of Nurses and Office Workers, 7(5), 1-10.

[29]. Yahyazadeh-jeloudar, S. (2012). Teachers' Emotional Intelligence and Its Relationship with Job Satisfaction, 1(1), 4-9.

[30]. Zahid, Q., Technologies, E., Wasim, N., Technologies, E., Raziq, S., \& Technologies, E. (n.d.). IMPACT OF EMOTIONAL INTELLIGENCE ON QUALITY OF.

[31]. Zhang, X., \& Li, B. (2013). Organizational Culture and Employee Satisfaction: An Exploratory Study, 4(1). 